\title{
Vorbemerkungen zum Text
}

1. Anordnung: Die beiden Hauptgattungen der bildenden Künste, Plastik und Malerei, wurden getrennt und zwar der Konsequenz halber auch dann, wenn sie in einem ursprünglichen Werkzusammenhang erscheinen, wie im Flügelaltar oder im geschnitzten Epitaph mit Gemälden. Die Nachteile dieser Trennung von Gesamtkunstwerken wurden auszugleichen versucht durch entsprechende Hinweise auf die anderen Teile sowie durch das Register. Innerhalb der Kunstgattungen ist die Anordnung chronologisch nach Stilperioden, innerhalb dieser alphabetisch nach Orten, gegliedert. Ein Abschnitt Kunsthandwerk ist angefügt, der jedoch die im Vorwort genannten Kunstgattungen ausschließt.

2. Bezeichnung und Bescbreibung wurden möglichst kurz gehalten im Hinblick auf die Abbildungen bzw. auf die Abbildungsverweise, konnten aber nicht wegfallen, da manche Einzelheiten nicht auf den Abbildungen erscheinen oder nur auf der Erinnerung des Bearbeiters beruhen.

3. Material: Dieses wurde nur in allgemeinster Form angegeben, da nähere Bestimmungen nachträglich nicht mehr möglich sind und sich auch in der früheren Literatur nur sehr summarisch fanden. An Holz für Bildhauerarbeiten wurde in den sächsischen Landen fast ausschließlich das Holz der Linde verwendet. Die Herkunft der seit dem 16. Jahrhundert vielfach verwendeten edleren Steinsorten ließ sich oft nicht mehr bestimmen, zumal da Alabaster in der älteren Literatur fast stets fälschlich als Marmor bezeichnet worden ist.

4. Maße: Soweit sie nicht in den Beschreibenden Darstellungen der Bau- und Kunstdenkmäler (BKD), den Museumskatalogen oder anderen Spezialveröffentlichungen angeführt waren, wurden sie nach bestem Wissen vom Bearbeiter schätzungsweise angegeben.

5. Farben: Auch hier konnte in vielen Fällen nur allgemein charakterisiert oder auf Teilstücke, wie Gewänder usw., bezügliche Angaben gemacht werden.

6. Zustand: Dieser konnte meist den erhaltenen Fotos entnommen werden, da diese nur in seltenen Fällen von dem Zustand zur Zeit der Zerstörung abwichen.

7. Ort: Es ist der ursprüngliche Standort des Werkes angegeben; der letzte Standort, etwa in einem Museum, nur dann, wenn der Herkunftsort nicht bekannt ist, da dieser der Rubrik „Zerstörung“ entnommen werden kann. Die Lage des Herkunftsortes ist durch seine Entfernung zur nächsten größeren Stadt bestimmt, nicht aber durch die öfter veränderte Kreis- bzw. Amtshauptmannschaftszugehörigkeit.

8. Datierung: Soweit nicht Daten am Werk angebracht oder schriftlich überliefert waren, ist die Entstehungszeit vom Bearbeiter geschätzt worden, wobei besonders für die frühesten Zeiten, aus 
denen nur wenige feste Datierungen bekannt sind, ein größerer Spielraum angenommen werden muß.

9. Kunstgeschichtliche Bemerkungen: Hier ist versucht worden, den ursprünglichen Werkzusammenhang, den zeit- und stilgeschichtlichen Zusammenhang (Entstehungsorte, Werkstatt, Meister) sowie etwa benutzte Vorlagen zu ermitteln und zu begründen. Verwandte oder ähnliche Werke, die verlorengingen, ohne daß Fotos von ihnen vorhanden sind, wurden entweder hier oder bei den Zerstörungsdaten erwähnt.

10. Zerstörung: Die Angaben unter dieser Rubrik können vielfach keinen Anspruch auf Vollständigkeit und absolute Richtigkeit erheben. Das Datum war nicht in allen Fällen sicher zu ermitteln, noch weniger die Zerstörungsursachen - ob Sprengbombentreffer, Brand durch Fliegerbomben verursacht, Artillerietreffer, späterer Einsturz infolge Beschädigungen usw. Für die Kriegsverluste im Museum des Sächsischen Altertumsvereins im Großen Garten zu Dresden wurde das Sigel „Vern. MSAV“ verwendet, womit zugleich der Zerstörungstag als 13. bzw. 14. Februar 1945 bezeichnet ist.

11. Literatur: Vollständigkeit wurde nicht angestrebt. Für solche wird auf die vom Bearbeiter verfaßte „Bibliographie zur Sächsischen Kunstgeschichte“, Berlin 1960, verwiesen. Ebenso wurde davon abgesehen, Schriften zu zitieren, die das betreffende Werk im wesentlichen nur zitieren oder meist irreführende Angaben bringen, wie z. B. Simon: Die figürliche Plastik der Oberlausitz. An erster Stelle werden stets entweder der betreffende Band der Beschreibenden Darstellung der Bauund Kunstdenkmäler (BKD) oder bei musealen Objekten der betreffende Museumskatalog bzw. Museumsführer angeführt. Dann folgen die wichtigsten kunsthistorischen Arbeiten, soweit sie dem Bearbeiter noch Gültigkeit zu beanspruchen scheinen; in ihnen ist meist die sonstige Literatur aufgeführt.

12. Fotonacbweis: Ausschlaggebend war die Stelle, welche das Negativ der Abbildung besitzt. Abbildungen ohne Herkunftsangaben stammen aus dem Institut für Denkmalpflege, Außenstelle Dresden. 